\title{
Expression and function of MutT homolog 1 in distinct subtypes of breast cancer
}

\author{
XIAOHUI ZHANG ${ }^{1 *}$, WEI SONG ${ }^{2 *}$, YIDONG ZHOU $^{1}$, FENG MAO $^{1}$, \\ YAN LIN $^{1}$, JINGHONG GUAN ${ }^{1}$ and QIANG SUN ${ }^{1}$ \\ ${ }^{1}$ Department of Breast Surgery, Peking Union Medical College Hospital; ${ }^{2}$ State Key Laboratory of Medical Molecular Biology, \\ Department of Biochemistry and Molecular Biology, Institute of Basic Medical Sciences, \\ Chinese Academy of Medical Sciences, Peking Union Medical College, Beijing 100730, P.R. China
}

Received September 28, 2015; Accepted December 9, 2016

DOI: $10.3892 / \mathrm{ol} .2017 .5726$

\begin{abstract}
Human MutT homolog 1 (MTH1) detoxifies the oxidized DNA precursor 8-oxo-2'-deoxyguanosine-5'-triphosphate and serves a tumor suppressive role in distinct types of cancer. In the present study, the expression of MTH1 was examined in various subtypes of breast cancer, and the effect of its suppression on breast cancer growth was characterized in vitro and in vivo. MTH1 mRNA and protein levels were assessed using the reverse transcription-quantitative polymerase chain reaction and immunohistochemistry. The effect of MTH1 expression on the proliferation of breast cancer cells was investigated in vitro using Cell Counting Kit-8 and colony formation assays, and in vivo using breast cancer cell line xenografts in mice. The toxicity of the MTH1 inhibitor TH588 was investigated in nude mice. A marked increase in MTH1 protein and mRNA levels was demonstrated in breast cancer tissues compared with the non-cancerous control. However, no apparent differences in MTH1 expression were observed between distinct molecular subtypes of breast cancer. MTH1 overexpression was demonstrated to be independent of patient age, tumor size and lymph node metastasis. Inhibition of MTH1 decreased cancer cell viability and the clonogenic potential of cancer cells in a dose-dependent manner. These results were confirmed by decreased in vivo proliferation of MCF7, MDA-MB-231 and MDA-MB-453 cancer cell lines, representing distinct subtypes of breast cancer. Although inhibition of MTH1 activity decreased xenograft growth in
\end{abstract}

Correspondence to: Dr Qiang Sun, Department of Breast Surgery, Peking Union Medical College Hospital, Chinese Academy of Medical Sciences, Peking Union Medical College, 1 Shuaifuyuan Street, Dongcheng, Beijing 100730, P.R. China

E-mail: sunqpumch@163.com

${ }^{*}$ Contributed equally

Key words: MutT homolog 1, TH588, luminal breast cancer, basal-like breast cancer, human epidermal growth factor receptor 2-positive breast cancer mice, no major adverse effects of TH588 were detected on the basis of blood biochemistry, and liver and kidney function. The results of the present study suggested that MTH1 is overexpressed in the majority of breast cancers, independent of the molecular identity and clinicopathological features of the tumor, including patient age, tumor size and lymph node metastasis. Inhibition of MTH1 activity suppressed the growth of three subtypes of breast cancer, including luminal, basal-like and human epidermal growth factor receptor 2-positive, in vitro and in vivo. Treatment with the MTH1 inhibitor appears to be safe; however, further studies are required prior to the clinical use of MTH1 inhibitors.

\section{Introduction}

Breast cancer is the most commonly diagnosed malignancy and the primary cause of cancer-associated mortality in women worldwide, with an annual estimate of 1.4 million new cases and $\sim 0.5$ million mortalities (1). Breast cancer is a heterogeneous disease with a range of clinical, pathological and molecular features (2-6). Molecular characterization of breast cancer has provided the basis for the classification and development of therapeutic strategies in patients with breast cancer (7). Based on the expression of estrogen receptor (ER), progesterone receptor (PR), human epidermal growth factor receptor 2 (Her-2) and proliferation marker protein $\mathrm{Ki}-67$, breast cancer may be classified into distinct molecular subtypes to assist in therapy recommendations. The luminal subtype $\left(\mathrm{ER}^{+} / \mathrm{PR}^{+}\right)$of breast cancer is regulated by estrogen and progesterone, and treatment typically requires endocrine therapy (8). The Her- $2^{+}$breast cancer subtype (ER-PR-Her- $2^{+}$) expresses Her-2, therefore these patients are treated using chemotherapy and Her-2-targeting inhibitors, including trastuzumab (8). Basal-like breast cancer cells do not express ER, PR and Her-2, therefore chemotherapy remains the only available therapeutic strategy, and these patients have a poor prognosis (9-12). Targeting oncogenic changes that drive cancer progression has been successful with the development of a number of drugs, including imatinib, dasatinib, vemurafenib and trastuzumab (13-16). However, this targeted approach is limited by the heterogeneity of tumors and the extensive cross-talk between the signaling pathways involved in cancer 
progression (16-18). Certain non-oncogenic proteins are not essential for the survival of wild-type cells; however, they are required to maintain the cancer phenotype (16). Targeting these proteins leads to the suppression of cancer and exhibits fewer side effects in wild-type tissues. As these functional proteins are independent of genetic changes, tumor heterogeneity and cross-talk with the tumor microenvironment, targeting these proteins may be applicable to a variety of tumor types (16). The human MutT homolog 1 (MTH1) enzyme has been identified to be a target for this type of therapeutic strategy (16). MTH1 is non-essential under normal conditions; however, it serves a role in oxidative stress, which is common in cancer (19). When oxidative damage occurs, reactive oxygen species (ROS) are produced, which lead to DNA oxidation (20-22). The oxidative product of guanine, 8-oxoguanine, causes $\mathrm{G}$ to $\mathrm{T}$ transversion mutations and may lead to cell death if allowed to accumulate in DNA (23-26). MTH1 hydrolyses and dephosphorylates 8 -oxoguanine and removes it from the nucleotide pool, thus excluding it from DNA synthesis $(26,27)$. The activity of MTH1 is required for the survival of cancer cells in environments of increased oxidative stress to avoid the incorporation of oxidized dNTPs; however, MTH1 activity is absent from wild-type tissues, suggesting that inhibition of MTH1 activity is unlikely to cause side effects $(19,28)$.

In the present study, the expression of MTH1 was examined in distinct subtypes of breast cancer and its role in the proliferation of breast cancer cells was characterized. The potential of targeting MTH1 as a therapeutic strategy for distinct subtypes of breast cancer was investigated. The potential toxicity of an MTH1 inhibitor, TH588, was also assessed in mice.

\section{Materials and methods}

Patient samples and cell lines. Tissue samples used for immunohistochemistry were collected from 30 female patients ( $\leq 50$ years old, $17 ;>50$ years old, 13 ) with breast cancer treated at Peking Union Medical College Hospital (PUMCH; Chinese Academy of Medical Sciences, Peking Union Medical College, Beijing, China) between August 2014 and December 2014. Tissues were fixed in $4 \%$ formaldehyde for $24 \mathrm{~h}$ at room temperature and paraffin-embedded. A total of 10 samples from each subtype (luminal, basal-like and Her- $2^{+}$) were randomly selected with a matched non-cancerous tissue dissected $>1 \mathrm{~cm}$ away from the tumor. Fresh samples used for reverse transcription-quantitative polymerase chain reaction (RT-qPCR) were obtained from a separate cohort of 30 female patients ( $\leq 50$ years old, $17 ;>50$ years old, 13 ) with breast cancer treated at PUMCH between December 2014 and February 2015, and flash-frozen in liquid nitrogen prior to use. Following pathological and histological confirmation, 10 samples of each subtype were selected randomly for RT-qPCR analysis. Written informed consent was obtained from all patients, and the study was approved by the Human Ethics Committee of PUMCH.

The MCF7, MDA-MB-231 and MDA-MB-453 cell lines, representing luminal, basal-like and Her-2 $2^{+}$subtypes of breast cancer, respectively, were purchased from the Cell Resource Center, Chinese Academy of Medical Sciences (CRC-CAMS; Peking Union Medical College, Beijing, China). The identity of the cell lines was confirmed by robust cell line authentication at CRC-CAMS.

A total of 40 female BALB/c-nu nude mice (5-6 weeks old) with body weights of $\sim 17 \mathrm{~g}$ were purchased from the Institute of Experimental Animals, Chinese Academy of Medical Sciences (Peking Union Medical College, Beijing, China) for use in the current study. All experimental procedures were approved by the Animal Ethics Committee of PUMCH. The mice had free access to water and food, a 12-h light cycle, and the temperature and the humidity were set at $26-28^{\circ} \mathrm{C}$ and $60 \%$, respectively.

Immunohistochemistry. Immunohistochemistry for MTH1 was performed according to previous protocol (29) and the manufacturer's protocol. Tissue sections (thickness, $3 \mu \mathrm{m}$ ) were deparaffinized in xylene and rehydrated using graded alcohol. Antigen retrieval was performed in buffer containing sodium citrate at $120^{\circ} \mathrm{C}$ for $1.5 \mathrm{~min}$. Sections were incubated for $1 \mathrm{~h}$ at $37^{\circ} \mathrm{C}$ with an anti-MTH1 antibody (dilution, 1:800; cat. no. ab98; Abcam, Cambridge, UK;) and developed with horseradish peroxidase (HRP)-conjugated anti-rabbit secondary antibody (dilution, 1:100; cat. no. ZF0511; ZSGB-Bio, Beijing, China) for $0.5 \mathrm{~h}$ at $37^{\circ} \mathrm{C}$. Images of stained sections were captured using a light microscope (Eclipse 80i; Nikon Corporation, Tokyo, Japan) and scored independently by two pathologists for the intensity of MTH1 staining, and for the percentage of tumor cells demonstrating MTH1 expression, providing an overall classification as negative ( $\leq 10 \%$ of cells exhibiting MTH1 staining) or positive ( $>10 \%$ of cells exhibiting MTH1 staining). According to the percentage of the stained cells, the positive staining groups were subdivided into weak (11-20\%), moderate $(21-50 \%)$ and strong (>50\%) expression groups.

$R T-q P C R$. MTH1 mRNA was quantified in 30 breast cancer and matching non-cancerous control tissues using RT-qPCR. Total RNA was isolated using a Total RNA Isolation kit (SBS Genetech, Beijing, China) and first-strand cDNA was synthesized using a Transcriptor First Strand cDNA Synthesis kit (Roche Diagnostics, Basel, Switzerland). qPCR was subsequently performed using a TransStart ${ }^{\circledR}$ Tip Green qPCR SuperMix (TransGen Biotech, Beijing, China) with $\beta$-actin as an internal control. All kits were used according to the manufacturer's protocol. The primers used were as follows: MTH1 forward, 5'-GTGCAGAACCCAGGGACCAT-3' and reverse, 5'-GCCCACGAACTCAAACACGA-3'; and $\beta$-actin forward, 5'-CCTGGCACCCAGCACAAT-3' and reverse, 5'-GGGCCG GACTCGTCATACT-3'. The qPCR thermocycling conditions, according to the kit manufacturer's protocol, were as follows: Initial denaturation at $94^{\circ} \mathrm{C}$ for $10 \mathrm{~min}, 39$ cycles consisting of an extension at $94^{\circ} \mathrm{C}$ for $10 \mathrm{sec}$ and at $60^{\circ} \mathrm{C}$ for $40 \mathrm{sec}$, followed by a final extension at $65^{\circ} \mathrm{C}$ for $5 \mathrm{~min}$. The $2^{-\Delta \Delta \mathrm{Cq}}$ method was used for the normalization of the data (30).

Cell culture. MCF7 cells were maintained in Dulbecco's modified Eagle's medium (GE Healthcare Life Sciences, Logan, UT, USA) containing $10 \%$ fetal bovine serum (Biological Industries, Kibbutz Beit-Haemek, Israel) at $37^{\circ} \mathrm{C}$ in a humidified atmosphere containing 5\% $\mathrm{CO}_{2}$. MDA-MB-231 and MDA-MB-453 cells were propagated in L15 medium (Corning Incorporated, Corning, NY, USA) supplemented 
with $10 \%$ fetal bovine serum at $37^{\circ} \mathrm{C}$ in a humidified atmosphere with no $\mathrm{CO}_{2}$.

Western blotting. Whole-cell lysates were prepared in radioimmunoprecipitation assay lysis buffer (Sigma-Aldrich; Merck Millipore, Darmstadt, Germany) containing a protease inhibitor cocktail (Sigma-Aldrich; Merck Millipore), followed by centrifugation at $16,000 \times \mathrm{g}$ for $20 \mathrm{~min}$ at $4^{\circ} \mathrm{C}$. The protein concentration in supernatants was determined using the Bradford protein assay (Bio-Rad Laboratories, Inc., Hercules, CA, USA). Proteins (50 $\mu \mathrm{g} /$ well) were separated using $12 \%$ SDS-PAGE under reducing conditions with 2-mercaptoethanol, transferred onto nitrocellulose membranes and blocked with $5 \%$ non-fat milk powder in TBS with $0.1 \%$ Tween-20 (TBST) for $2 \mathrm{~h}$ at room temperature. Membranes were incubated with rabbit anti-MTH1 (dilution, 1:500) and rabbit anti- $\alpha$-tubulin (dilution, 1:500; cat. no. sbr001; Saier Biotech, Tianjin, China) antibodies diluted in blocking buffer overnight at $4^{\circ} \mathrm{C}$, washed with TBST, and incubated with an HRP-conjugated secondary antibody at room temperature for $1.5 \mathrm{~h}$. Signals were visualized using Western Lightning ${ }^{\mathrm{TM}}$ Chemiluminescence reagent according to the manufacturer's protocol (PerkinElmer, Inc., Waltham, MA, USA) and images were captured using LabWorks software (PerkinElmer, Inc., version 4.6).

Cell viability assay. Cell viability was assessed using a Cell Counting Kit-8 assay (Engreen Biosystem Ltd., Beijing, China) according to the manufacturer's instructions. Briefly, cells $(5,000$ cells/well) were plated in 96 -well plates and were allowed to attach for $8 \mathrm{~h}$ at $37^{\circ} \mathrm{C}$ prior to treatment with 2, 4, 6, 8, 10, 16 and $20 \mu \mathrm{M}$ TH588 (Selleck Chemicals, Houston, TX, USA). The viability was determined following $72 \mathrm{~h}$ of treatment at $37^{\circ} \mathrm{C}$ by measuring the absorbance at $450 \mathrm{~nm}$ using a Multiskan Spectrum spectrophotometer (Thermo Fisher Scientific, Waltham, MA, USA).

Colony formation assay. Fully dissociated cells (1,000 cells/well) were plated in 6-well plates and allowed to attach for $5 \mathrm{~h}$ at $37^{\circ} \mathrm{C}$ prior to treatment with TH588. Cells were cultured for $1-2$ weeks at $37^{\circ} \mathrm{C}$, depending on the cell line (MCF7 for 1 week, MDA-MB-231 for 1.5 weeks and MDA-MB-453 for 2 weeks). Colonies were fixed with $4 \%$ paraformaldehyde in PBS for $0.5 \mathrm{~h}$ at $4^{\circ} \mathrm{C}$, stained with crystal violet, and colonies with $>50$ cells were counted with a light microscope manually. Relative colony formation rates at various drug concentrations were obtained by comparing with non-drug-treated control cells.

Mouse xenograft assay. Cancer cells ( $3 \times 10^{7}$ cells/mouse) were inoculated subcutaneously into the left axilla of 5-week-old female nude mice $(n=30)$. Mice were maintained under general animal husbandry conditions, except for those carrying MCF-7 xenografts, which were administered daily with estradiol benzoate ( $3 \mu \mathrm{g} / \mathrm{mouse}$ ) for the course of the assay. Following the growth of tumors to a visible size $(\sim 2 \mathrm{~mm}$ in mean diameter; typically between 10 and 14 days following inoculation), mice were randomly grouped (5 mice/treatment) for daily subcutaneous TH588 $(30 \mathrm{mg} / \mathrm{kg})$ or vehicle (2\% dimethylsulfoxide, $10 \%$ ethanol, $10 \%$ cremophor (Sigma-Aldrich; Merck-Millipore) and 10\% Tween-80 in PBS) treatment.
Tumor size was determined using a calliper three times/week and mouse body weight was recorded. The treatment period was between 2 and 3 weeks depending on the tumor growth. The mice were sacrificed by cervical dislocation.

In vivo toxicity assay. Nude mice (6-week-old) with no tumor burden were administered with TH588 or vehicle as described above. Mice were weighed daily and $300 \mu 1$ of blood was collected by retro-orbital bleeding at the end of the experiment. Toxicity was assessed by determining the number of red and white blood cells, and platelets using an LH 750 Hematology Analyzer (Beckman Coulter, Inc., Brea, CA, USA). The levels of alanine aminotransferase, aspartate aminotransferase and creatinine in serum were determined using a UniCel DxC 600 Synchron Biochemical Analyzer (Beckman Coulter, Inc.).

Statistical analysis. Results were analyzed using SPSS version 17.0 (SPSS, Inc., Chicago, IL, USA). Data were presented as the mean \pm standard deviation. Statistical significance was calculated using a $\chi^{2}$ test, independent t-test (of normally distributed variables) or Mann-Whitney $U$ test (of non-normally distributed variables). $\mathrm{P}<0.05$ was considered to indicate a statistically significant difference.

\section{Results}

Expression of MTH1 is increased in the primary subtypes of breast cancer. MTH1 protein expression was evaluated using immunohistochemistry on paraffin-embedded samples from patients with breast cancer using non-cancerous breast tissues as a control. Among the 30 cancer samples evaluated, 10 were luminal, 10 were basal-like and 10 were of Her-2 $2^{+}$subtype. The clinicopathological characteristics of the patients are presented in Table I. There was no significant difference between the age of patients, tumor sizes and lymph node metastasis. Strong expression of MTH1 protein was demonstrated in 27/30 patient samples, moderate expression was demonstrated in 1 patient sample (basal-like subtype) and weak expression was demonstrated in 2 patient samples (both Her-2 $2^{+}$subtype; Fig. 1). By contrast, MTH1 expression in non-cancerous tissues was weak in 6 patient samples, moderate in 1 patient sample, and negative in 3 patient samples (Fig. 1). Expression of MTH1 was significantly upregulated in breast cancer tissue compared with non-cancerous tissue $(\mathrm{P}<0.001$; Table II). However, no significant difference in MTH1 expression between the distinct subtypes of breast cancer was identified, and MTH1 expression was not significantly associated with patient age, tumor size or the grade of lymph node metastasis (Table III).

To confirm the increase in MTH1 expression in breast cancer, MTH1 mRNA levels were determined using RT-qPCR using total RNA isolated from fresh cancer tissues collected from a separate cohort of 30 patients with breast cancer. A total of 30 matched non-cancerous tissues were used as a control. The clinicopathological characteristics are presented in Table IV. Using $\beta$-actin as a loading control, the relative abundance of MTH1 transcripts was examined (Table V). The results indicated a 3.15-fold increase in MTH1 mRNA levels in 30 breast cancer tissues compared with the non-cancerous tissues $(\mathrm{P}=0.003)$. However, no significant difference in 
Table I. Clinicopathological characteristics of the patients assessed using immunohistochemical analysis.

\begin{tabular}{|c|c|c|c|c|c|}
\hline Characteristic & Luminal & Basal-like & Her- $2^{+}$ & Total & P-value ${ }^{a}$ \\
\hline Age, years & & & & & $>0.05$ \\
\hline$\leq 50$ & 5 & 6 & 6 & 17 & \\
\hline$>50$ & 5 & 4 & 4 & 13 & \\
\hline Tumor size, $\mathrm{cm}$ & & & & & $>0.05$ \\
\hline$\leq 2$ & 5 & 4 & 7 & 16 & \\
\hline$>2$ & 5 & 6 & 3 & 14 & \\
\hline Lymph node metastasis & & & & & $>0.05$ \\
\hline Positive & 5 & 3 & 4 & 12 & \\
\hline Negative & 5 & 7 & 6 & 18 & \\
\hline
\end{tabular}

${ }^{a}$ Multiple comparisons among the luminal group, basal-like group and Her-2 group. Her-2, human epidermal growth factor receptor 2.

Table II. Expression of MutT homolog 1 protein in tumor and wild-type breast tissue.

\begin{tabular}{lcccc}
\hline Tissue & $\begin{array}{c}\text { Strong/ } \\
\text { moderate }\end{array}$ & $\begin{array}{c}\text { Weak/ } \\
\text { negative }\end{array}$ & $\chi^{2}$ & P-value \\
\hline Tumor & 28 & 2 & 22.11 & $<0.001$ \\
Wild-type breast & 1 & 9 & & \\
\hline
\end{tabular}

MTH1 mRNA levels was identified between distinct subtypes of breast cancer, and the MTH1 mRNA levels were not significantly associated with patient age, tumor size, or progression to lymph node metastasis.

Inhibiting MTH1 decreases cell viability in vitro. To characterize the effects of MTH1 on breast cancer progression, three breast cancer cell lines, MCF7, MDA-MB-231 and MDA-MB-453, representing luminal, basal-like and Her- $2^{+}$subtypes of breast cancer (31-33), respectively, were analysed for MTH1 expression using western blotting. Consistent with results using patient samples, cell lines representing these three types of breast cancer had similar levels of MTH1 expression (Fig. 2A).

TH588, a cell-permeant small-molecule inhibitor of MTH1, was used to investigate how inhibition of MTH1 affects the viability of breast cancer cells. It was demonstrated that TH588 decreased the survival of MCF7, MDA-MB-231 and MDA-MB-453 cells, although the viability of Her-2+ MDA-MB-453 cells was decreased less compared with the other two cell lines (Fig. 2B).

The effect of MTH1 inhibition on breast cancer cell proliferation was assessed using a colony formation assay. MCF7, MDA-MB-231 and MDA-MB-453 cells were treated with various concentrations of TH588 for between 1 and 2 weeks. It was demonstrated that TH588 decreased the number of colonies in a concentration-dependent manner in all three breast cancer lines (Fig. 2C-E). The half-maximal inhibitory concentration values for TH588 were 9.78, 6.96 and $8.97 \mu \mathrm{M}$ in MCF7, MDA-MB-231 and MDA-MB-453 cells, respectively (Fig. 2F).
Table III. MutT homolog 1 protein expression in breast cancer tissues with various clinicopathological backgrounds.

\begin{tabular}{lccc}
\hline Characteristic & $\begin{array}{c}\text { Strong/ } \\
\text { moderate }\end{array}$ & $\begin{array}{c}\text { Weak/ } \\
\text { negative }\end{array}$ & P-value \\
\hline Her-2 & 20 & 0 & $>0.05$ \\
$\quad$ Negative & 8 & 2 & \\
$\quad$ Positive & & & $>0.05$ \\
Age, years & 16 & 1 & \\
$\quad \leq 50$ & 12 & 1 & \\
$>50$ & 14 & 2 & $>0.05$ \\
Tumor size, cm & 14 & 0 & \\
$\quad \leq 2$ & & & $>0.05$ \\
$>2$ & 11 & 1 & \\
Lymph node metastasis & 17 & 1 & \\
Positive & & & \\
Negative & & & \\
\hline
\end{tabular}

${ }^{\mathrm{a}}$ Comparisons between the strong/moderate group and weak/negative group. Her-2, human epidermal growth factor receptor 2.

MTH1 inhibition suppresses tumor growth in vivo. To further confirm the role of MTH1 in breast cancer, the effect of MTH1 inhibition on tumor growth was examined using a mouse xenograft model. MCF7, MDA-MB-231 and MDA-MB-453 cells were inoculated subcutaneously into the left axilla of mice. Following establishment of tumors, daily TH588 treatments were administered while control mice were treated with the vehicle control only. As presented in Fig. 3A, TH588 treatment gradually suppressed the growth of MCF7 and MDA-MB-231 tumors, and 1 week following the first treatment the tumors began to shrink. The growth of MCF7 xenografts was inhibited by $92.7 \%(\mathrm{P}=0.001$; data not shown) and TH588 treatment caused a $90.4 \%$ regression of MDA-MB-231 xenografts $(\mathrm{P}=0.001$; data not shown). The effect of MTH1 inhibition was most marked in the MDA-MB-453 xenograft model, where TH588 completely 
Table IV. Clinicopathological characteristics of patients recruited for reverse transcription-quantitative polymerase chain reaction analysis.

\begin{tabular}{|c|c|c|c|c|c|}
\hline Characteristic & Luminal & Basal-like & Her- $2^{+}$ & Total & P-value ${ }^{a}$ \\
\hline Age, years & & & & & $>0.05$ \\
\hline$\leq 50$ & 6 & 5 & 6 & 17 & \\
\hline$>50$ & 4 & 5 & 4 & 13 & \\
\hline Tumor size, $\mathrm{cm}$ & & & & & $>0.05$ \\
\hline$\leq 2$ & 5 & 3 & 4 & 12 & \\
\hline$>2$ & 5 & 7 & 6 & 18 & \\
\hline Lymph node metastasis & & & & & $>0.05$ \\
\hline Positive & 6 & 4 & 7 & 17 & \\
\hline Negative & 4 & 6 & 3 & 13 & \\
\hline
\end{tabular}

${ }^{a}$ Multiple comparisons among the luminal group, basal-like group and Her-2 group. Her-2, human epidermal growth factor receptor 2.

Table V. Expression of MutT homolog 1 mRNA in breast cancer.

\begin{tabular}{lccc}
\hline & $\begin{array}{c}\text { No. } \\
\text { of cases }\end{array}$ & $\begin{array}{c}\text { MTH1 } \\
\text { mRNA }\end{array}$ & P-value \\
\hline $\begin{array}{l}\text { Non-cancerous tissue } \\
\text { Cancer }\end{array}$ & 30 & $3.15 \pm 1.67$ & 0.003 \\
Subtype & 30 & $1.00 \pm 0.00$ & \\
$\quad$ Luminal & 10 & $3.28 \pm 1.76$ & $>0.05$ \\
$\quad$ Basal-like & 10 & $3.22 \pm 1.83$ & \\
Her-2 & 10 & $2.93 \pm 1.55$ & \\
Age, years & & & $>0.05$ \\
$\quad \leq 50$ & 17 & $3.21 \pm 1.75$ & \\
$\quad>50$ & 13 & $3.11 \pm 1.56$ & \\
Tumor size, cm & & & $>0.05$ \\
$\quad \leq 2$ & 12 & $3.04 \pm 1.83$ & \\
$>2$ & 18 & $3.18 \pm 1.63$ & \\
Lymph node metastasis & & & $>0.05$ \\
$\quad$ Positive & 17 & $3.29 \pm 1.90$ & \\
$\quad$ Negative & 13 & $3.07 \pm 1.52$ & \\
\hline
\end{tabular}

Her-2, human epidermal growth factor receptor 2.

eradicated tumors by the end of the experiment (data not shown). These results suggested that targeting MTH1 induced marked tumor regression in mice.

Inhibiting MTH1 affects mouse growth. During mouse xenograft experiments, the growth of mice was monitored to assess the potential effect of MTH1 inhibition on mice. It was observed that, whereas mice in the control group continued to grow, mice treated with TH588 ceased growth at between 5 and 8 days following initial treatment (Fig. 3C). Although no mice succumbed to TH588 treatment, a plot of body weight against time indicated an inhibitory effect of TH588 on the growth of mice (Fig. 3C).
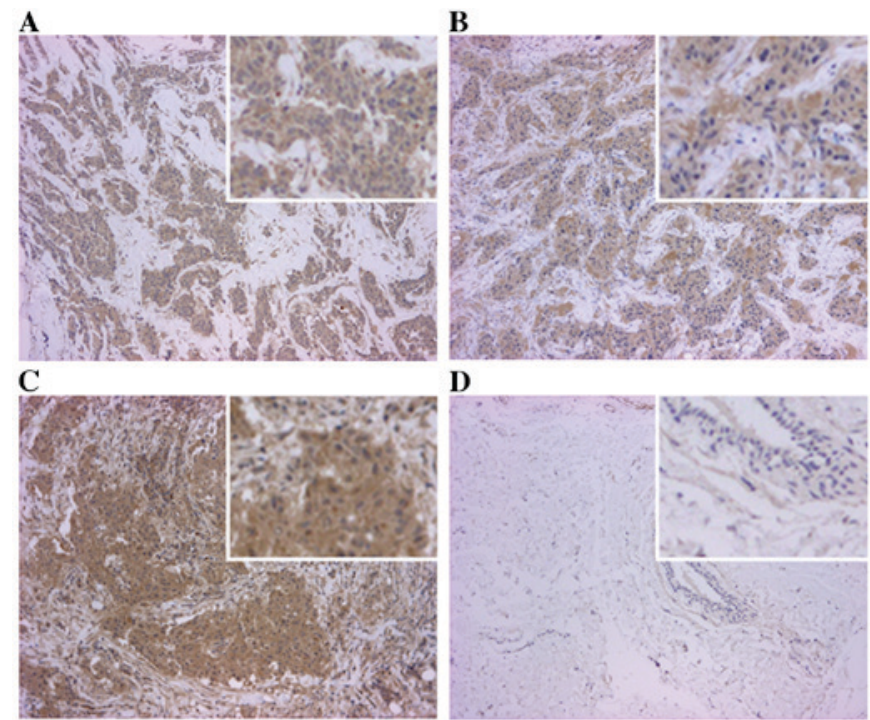

D

Figure 1. MutT homolog 1 expression is increased in luminal (A), human epidermal growth factor receptor 2-positive (B) and basal-like (C) breast cancer compared with (D) wild-type breast tissue. Magnification, x40; insets, $\mathrm{x} 100$.

Results of independent toxicity studies using mice with no tumor burden identified an inhibitory effect of TH588 on the growth of mice (Fig. 3D). However, no clear effect of TH588 on blood chemistry or liver function was observed (Table VI), suggesting that TH588 treatment was tolerable during the experimental period.

\section{Discussion}

Improvements in clinical outcomes of patients with breast cancer have been limited, particularly for basal-like breast cancer, endocrine-therapy-resistant luminal tumors and trastuzumab non-responsive Her- $2^{+}$type cancer. The dependence of cancer cells, either oncogenic or non-oncogenic, on certain signaling pathways and on metabolic changes, that confer sustained proliferation and survival potential on cancer 
$\mathbf{A}$

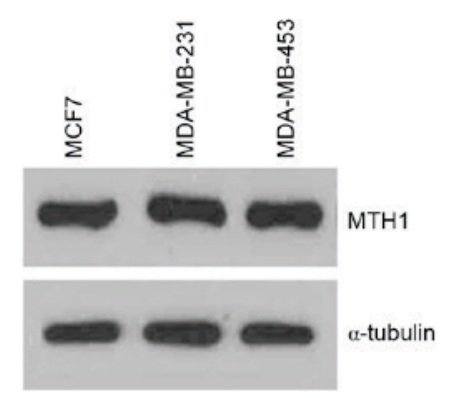

C

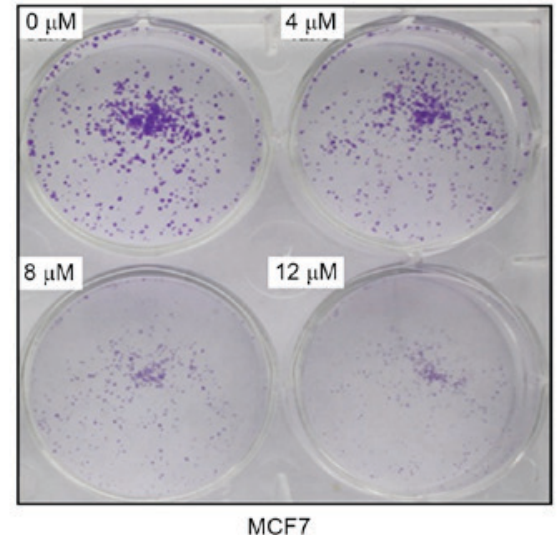

$\mathbf{E}$

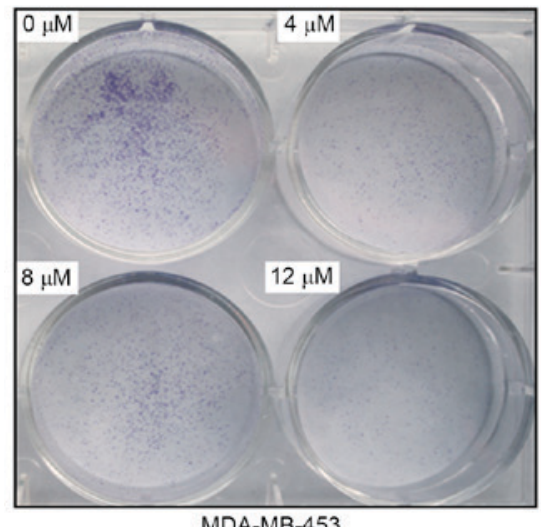

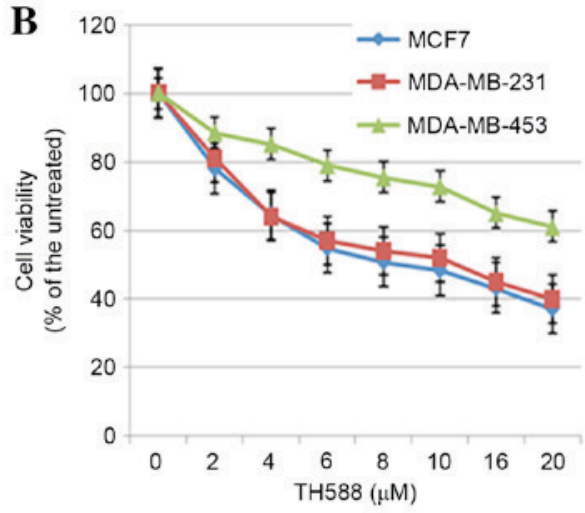

D

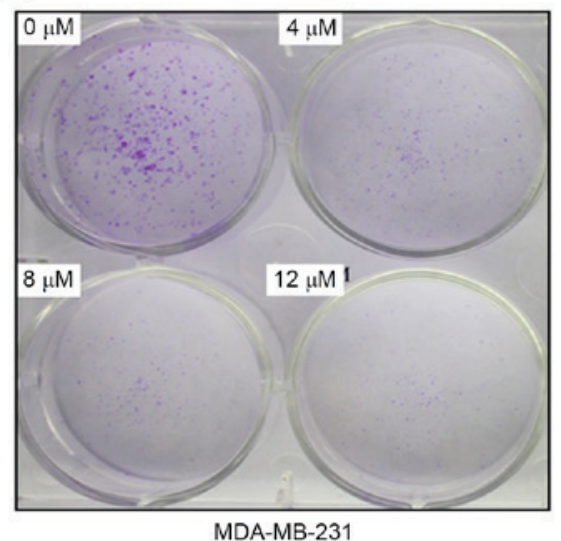

$\mathbf{F}$

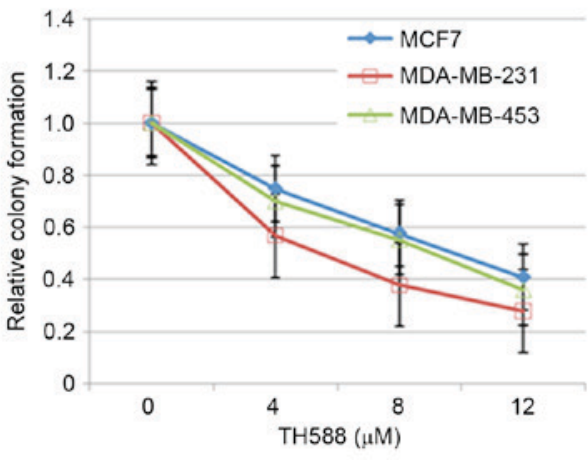

Figure 2. MTH1 is essential for the survival and proliferation of breast cancer cells in vitro. (A) The expression of MTH1 in MCF7, MDA-MB-231 and MDA-MB-453 cell lines was detected using western blotting. (B) Inhibition of MTH1 reduced cell viability in MCF7, MDA-MB-231 and MDA-MB-453 cells. Colony formation assays of (C) MCF7, (D) MDA-MB-231 and (E) MDA-MB-453 cells with TH588 at various concentrations. (F) Quantification of colony formation assays. MTH1, MutT homolog 1.

cells, provides a basis for therapeutic strategies (16). Phenotypic lethality strategies target non-oncogenic biochemical or metabolic features which are critical in the maintenance of the cancer phenotype; however, they are dispensable in wild-type tissue. MTH1 is such a target with evidence obtained in colorectal cancer and in osteosarcomas (19).

In the present study, the effects of targeting MTH1, an enzyme that detoxifies oxidized deoxynucleoside triphosphate (dNTP) pools to prevent the incorporation of damaged bases during DNA replication, were investigated in breast cancer. It was demonstrated that MTH1 is upregulated in breast cancer compared with wild-type tissue, independent of patient age, tumor size or lymph node metastasis. These results are consistent with previous findings that MTH1 is increased in gastric and colorectal cancer $(34,35)$. Increased levels of MTH1 are consistent with increased production of ROS resulting from the active metabolism in cancer cells and oxidative stress as MTH1 is essential for the removal of oxidized dNTPs from cells.

It was demonstrated that inhibition of MTH1 by TH588 decreased cell viability and clonogenic potential in all three breast cancer cell lines examined. These results suggest an 
Table VI. Effect of TH588 on the blood chemistry and liver function of mice.

\begin{tabular}{lccc}
\hline Component & TH588-treated & Vehicle-treated & P-value \\
\hline White blood cells $\left(10^{9}\right.$ cells/l) & $4.23 \pm 1.81$ & $4.17 \pm 1.53$ & $>0.05$ \\
Red blood cells $\left(10^{12}\right.$ cells/l) & $9.51 \pm 3.14$ & $9.78 \pm 3.01$ & $>0.05$ \\
Platelet $\left(10^{9}\right.$ cells/l) & $711.15 \pm 237.17$ & $687.34 \pm 200.11$ & $>0.05$ \\
Alanine aminotransferase (units/l) & $43.07 \pm 17.18$ & $39.11 \pm 13.45$ & $>0.05$ \\
Aspartate aminotransferase (units/l) & $78.09 \pm 25.56$ & $83.11 \pm 24.92$ & $>0.05$ \\
Creatinine $($ mmol/l) & $75.26 \pm 19.72$ & $78.17 \pm 18.27$ & $>0.05$
\end{tabular}

$\mathbf{A}$

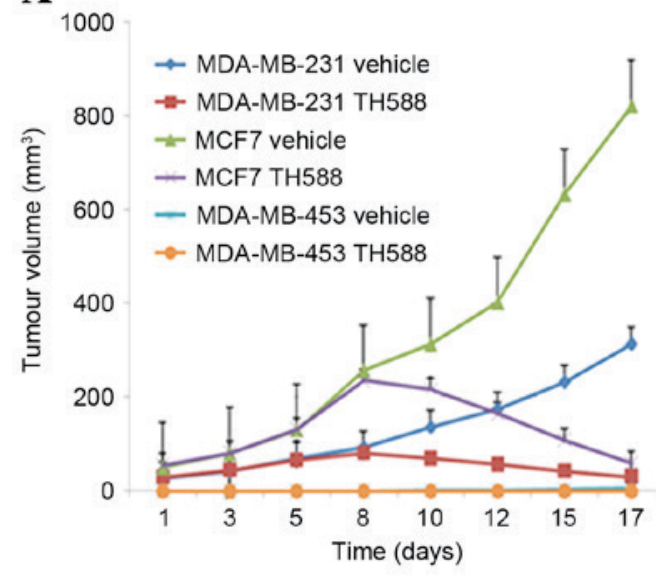

C

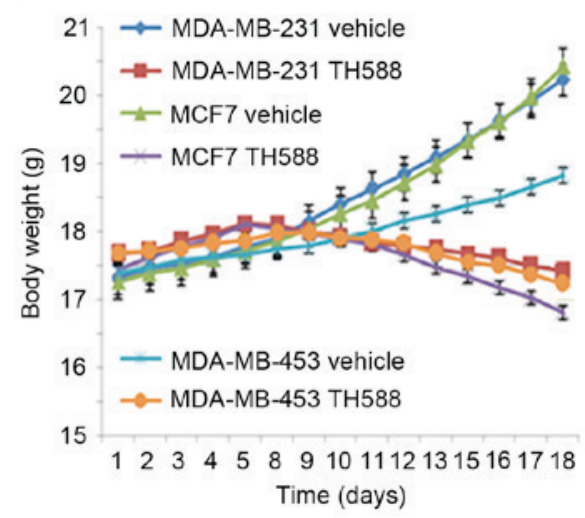

B

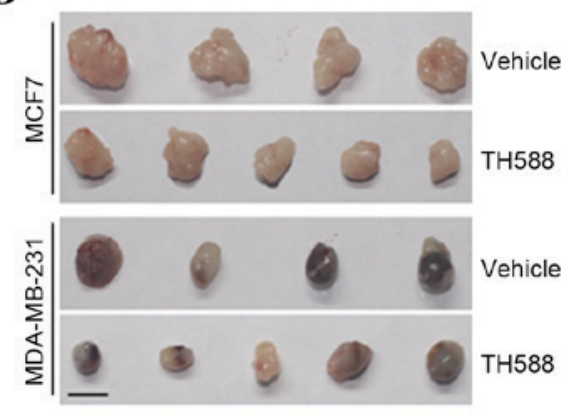

D

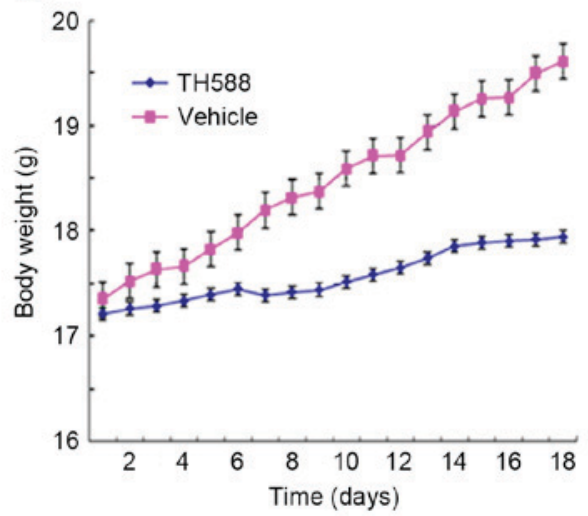

Figure 3. Inhibition of MutT homolog 1 by TH588 causes tumor regression in mice. (A) MCF7, MDA-MB-231 and MDA-MB-453 cells were inoculated subcutaneously into the left axilla of the mice. Daily TH588 administration began when tumors reached a certain size (2 mm). (B) Representative xenografts of MCF7 and MDA-MB-231 cells generated in mice treated with vehicle or TH588; MDA-MB-453 xenografts are not presented as they were completely inhibited following TH588 treatment. Scale bar, $1 \mathrm{~cm}$. (C) Effect of TH588 on body weight of mice carrying MCF7, MDA-MB-231 and MDA-MB-453 tumors. (D) Effect of TH588 on body weight in mice without tumor burden.

essential role for MTH1 in cancer cell survival, consistent with previous findings in colorectal cancer (19). Although cell viability data suggested that MDA-MB-453 cells are less sensitive to MTH1 inhibition, all three cell lines exhibited a similar sensitivity to MTH1 inhibition in a colony formation assay.

Inhibition of MTH1 using TH588 significantly inhibited the growth of breast cancer xenografts. For MCF7 and MDA-MB-231 cells, representing luminal and basal-like subtypes of breast cancer, respectively, a $>90 \%$ regression of tumor growth was observed within 17 days. The Her-2+ MDA-MB-453 tumors were completely eradicated, suggesting a promising inhibitory effect of TH588 on the growth of tumors in vivo. These results are consistent with previous findings in melanoma and colorectal cancer cells using various inhibitors of MTH1 $(19,28)$, suggesting that targeting MTH1 warrants further investigation as a treatment strategy for various malignancies. However, it is noteworthy that the present study was performed using established cancer cell lines and further studies using patient-derived xenografts are required.

It was demonstrated that MTH1 inhibition appears to decrease the growth of mice. Although a statistically significant loss of body weight in TH588-treated mice was not observed, 
and blood chemistry and liver function remained normal, further studies are required to optimize the administration regime and to determine the therapeutic window for MTH1 inhibition in vivo.

In conclusion, the results of the present study demonstrate that MTH1 is upregulated in all three major subtypes of breast cancer, and that MTH1 is essential for the proliferation of breast cancer cells in vitro and in vivo. The results of the present study suggest that targeting MTH1 affects cell viability and colony formation, and induces tumor regression in mice within a short time period. In addition, MTH1 inhibition by TH588 was not observed to exhibit an effect on blood and liver function, suggesting that targeting MTH1 may be tolerable.

\section{References}

1. Jemal A, Center MM, DeSantis C and Ward EM: Global patterns of cancer incidence and mortality rates and trends. Cancer Epidemiol Biomarkers Prev 19: 1893-1907, 2010.

2. Cancer Genome Atlas Network: Comprehensive molecular portraits of human breast tumours. Nature 490: 61-70, 2012.

3. Perou CM, Sørlie T, Eisen MB, van de Rijn M, Jeffrey SS, Rees CA, Pollack JR, Ross DT, Johnsen H, Akslen LA, et al: Molecular portraits of human breast tumours. Nature 406: 747-752, 2000.

4. Sorlie T, Perou CM, Tibshirani R, Aas T, Geisler S, Johnsen H, Hastie T, Eisen MB, van de Rijn M, Jeffrey SS, et al: Gene expression patterns of breast carcinomas distinguish tumor subclasses with clinical implications. Proc Natl Acad Sci USA 98: 10869-10874, 2001.

5. O'Brien KM, Cole SR, Tse CK, Perou CM, Carey LA, Foulkes WD, Dressler LG, Geradts J and Millikan RC: Intrinsic breast tumor subtypes, race, and long-term survival in the Carolina Breast Cancer Study. Clin Cancer Res 16: 6100-6110, 2010.

6. Carey LA, Perou CM, Livasy CA, Dressler LG, Cowan D, Conway K, Karaca G, Troester MA, Tse CK, Edmiston S, et al: Race, breast cancer subtypes, and survival in the Carolina Breast Cancer Study. JAMA 295: 2492-2502, 2006.

7. Parise CA and Caggiano V: Breast cancer survival defined by the ER/PR/HER2 subtypes and a surrogate classification according to tumor grade and immunohistochemical biomarkers. J Cancer Epidemiol 2014: 469251, 2014.

8. Goldhirsch A, Wood WC, Coates AS, Gelber RD, Thurlimann B and Senn HJ; Panel members: Strategies for subtypes-dealing with the diversity of breast cancer: Highlights of the St. Gallen international expert consensus on the primary therapy of early breast cancer 2011. Ann Oncol 22: 1736-1747, 2011.

9. Zhang XH, Sun Q, Zhou YD, Mao F, Guan JH and Lin Y: Association of molecular subtyping with clinicopathologic features and prognosis in breast cancer patients with axillary lymph node metastasis. Tumor 33: 271-275, 2013.

10. Zhang XH, Xu YL, Sun Q, Pan B, Zhou Y, Mao F, Guan J and Lin Y: Molecular subtype and its association with prognosis in axillary lymph node-negative invasive breast cancer patients. Chin J Clin Oncol 12: 793-796, 2014 (In Chinese).

11. Pracella D, Bonin S, Barbazza R, Sapino A, Castellano I, Sulfaro S and Stanta G: Are breast cancer molecular classes predictive of survival in patients with long follow-up? Dis Markers 35: 595-605, 2013.

12. de Ruijter TC, Veeck J, de Hoon JP, van Engeland M and Tjan-Heijnen VC: Characteristics of triple-negative breast cancer. J Cancer Res Clin Oncol 137: 183-192, 2011.

13. Gnoni A, Marech I, Silvestris N, Vacca A and Lorusso V: Dasatinib: An anti-tumour agent via Src inhibition. Curr Drug Targets 12: 563-578, 2011.

14. Araujo J and Logothetis C: Dasatinib: A potent SRC inhibitor in clinical development for the treatment of solid tumors. Cancer Treat Rev 36: 492-500, 2010.

15. Balduzzi S, Mantarro S, Guarneri V, Tagliabue L, Pistotti V, Moja L and D'Amico R: Trastuzumab-containing regimens for metastatic breast cancer. Cochrane Database Syst Rev 6: CD006242, 2014.
16. Helleday T: Cancer phenotypic lethality, exemplified by the non-essential MTH1 enzyme being required for cancer survival. Ann Oncol 25: 1253-1255, 2014.

17. Melisi D, Piro G, Tamburrino A, GCarbone D and Tortora G: Rationale and clinical use of multitargeting anticancer agents. Curr Opin Pharmacol 13: 536-542, 2013.

18. Cheng L, Ren W, Xie L, Li M, Liu J, Hu J, Liu BR and Qian XP: Anti-EGFR MoAb treatment in colorectal cancer: Limitations, controversies, and contradictories. Cancer Chemother Pharmacol 74: 1-13, 2014.

19. Gad H, Koolmeister T, Jemth AS, Eshtad S, Jacques SA, Ström CE, Svensson LM, Schultz N, Lundbäck T, Einarsdottir BO, et al: MTH1 inhibition eradicates cancer by preventing sanitation of the dNTP pool. Nature 508: 215-221, 2014.

20. Indo HP, Davidson M, Yen HC, Suenaga S, Tomita K, Nishii T, Higuchi M, Koga Y, Ozawa T and Majima HJ: Evidence of ROS generation by mitochondria in cells with impaired electron transport chain and mitochondrial DNA damage. Mitochondrion 7: 106-118, 2007.

21. Sridharan DM, Asaithamby A, Bailey SM, Costes SV, Doetsch PW, Dynan WS, Kronenberg A, Rithidech KN, Saha J, Snijders AM, et al: Understanding cancer development processes after HZE-particle exposure: Roles of ROS, DNA damage repair and inflammation. Radiat Res 183: 1-26, 2015.

22. Strickertsson JA, Desler C, Martin-Bertelsen T, Machado AM, Wadstrøm T, Winther O, Rasmussen LJ and Friis-Hansen L: Enterococcus faecalis infection causes inflammation, intracellular oxphos-independent ROS production, and DNA damage in human gastric cancer cells. PLoS One 8: e63147, 2013.

23. Yoshimura D, Sakumi K, Ohno M, Sakai Y, Furuichi M, Iwai S and Nakabeppu Y: An oxidized purine nucleoside triphosphatase, MTH1, suppresses cell death caused by oxidative stress. J Biol Chem 278: 37965-37973, 2003.

24. Yang Y, Karakhanova S, Werner J and Bazhin AV: Reactive oxygen species in cancer biology and anticancer therapy. Curr Med Chem 20: 3677-3692, 2013.

25. Nakabeppu Y: Cellular levels of 8-oxoguanine in either DNA or the nucleotide pool play pivotal roles in carcinogenesis and survival of cancer cells. Int J Mol Sci 15: 12543-12557, 2014.

26. Scott TL, Rangaswamy S, Wicker CA and Izumi T: Repair of oxidative DNA damage and cancer: Recent progress in DNA base excision repair. Antioxid Redox Signal 20: 708-726, 2014.

27. Furuichi M, Yoshida MC, Oda H, Tajiri T, Nakabeppu Y, Tsuzuki T and Sekiguchi M: Genomic structure and chromosome location of the human mutT homologue gene MTH1 encoding 8-oxo-dGTPase for prevention of A:T to C:G transversion. Genomics 24: 485-490, 1994.

28. Huber KV, Salah E, Radic B, Gridling M, Elkins JM, Stukalov A, Jemth AS, Göktürk C, Sanjiv K, Strömberg K, et al: Stereospecific targeting of MTH1 by (S)-crizotinib as an anticancer strategy. Nature 508: 222-227, 2014.

29. Duerr JS: Immunohistochemistry. WormBook: 1-61, 2006.

30. Livak KJ and Schmittgen TD: Analysis of relative gene expression data using real-time quantitative PCR and the 2(-Delta Delta C(T)) method. Methods 25: 402-408, 2001.

31. Subik K, Lee JF, Baxter L, Strzepek T, Costello D, Crowley P, Xing L, Hung MC, Bonfiglio T, Hicks DG and Tang P: The expression patterns of ER, PR, HER2, CK5/6, EGFR, Ki-67 and AR by immunohistochemical analysis in breast cancer cell lines. Breast Cancer (Auckl) 4: 35-41, 2010.

32. Ithimakin S, Day KC, Malik F, Zen Q, Dawsey SJ, Bersano-Begey TF, Quraishi AA, Ignatoski KW, Daignault S, Davis A, et al: HER2 drives luminal breast cancer stem cells in the absence of HER2 amplification: Implications for efficacy of adjuvant trastuzumab. Cancer Res 73: 1635-1646, 2013.

33. Shim JS, Rao R, Beebe K, Neckers L, Han I, Nahta R and Liu JO: Selective inhibition of HER2-positive breast cancer cells by the HIV protease inhibitor nelfinavir. J Natl Cancer Inst 104: 1576-1590, 2012.

34. Koketsu S, Watanabe T and Nagawa H: Expression of DNA repair protein: MYH, NTH1, and MTH1 in colorectal cancer. Hepatogastroenterology 51: 638-642, 2004.

35. Borrego S, Vazquez A, Dasí F, Cerdá C, Iradi A, Tormos C, Sánchez JM, Bagán L, Boix J, Zaragoza C, et al: Oxidative stress and DNA damage in human gastric carcinoma: 8-Oxo-7'8-dihydro-2'-deoxyguanosine (8-oxo-dG) as a possible tumor marker. Int J Mol Sci 14: 3467-3486, 2013. 